\title{
Exercise Testing of Patients after a Period of Prolonged Mechanical Ventilation
}

\begin{abstract}
In this study, physical recovery of patients who received prolonged mechanical ventilation (PMV) was assessed with a six-phase functional exercise test after the period of ventilation. A prospective correlation study using a consecutive sampling method was carried out over a six-month period. Thirty-one patients were tested but five were lost to follow-up. Statistical tests included the Pearson's correlation coefficient, student's paired t-test and Kaplan-Meier survival estimate. Subjective perceived effort changed significantly from phase to phase in the exercise test and over time $(p<0.00)$. Heart rate and respiratory rate responses indicated increased cardio-respiratory effort during the test. No correlation existed between subjective perceived

\section{Roos R, BSc'; Van Asw egen $\mathrm{H}, \mathrm{MSc}^{2}$; Eales CJ, PhD; Becker PJ, PhD}

1 Stellenbosch University.

2 Supervisor, University of the W itwatersrand.

3 Supervisor, Biostatistics unit at the MRC. effort and cardio-respiratory parameters. Minimal improvement was noted in cardio-respiratory parameters over time and signs of respiratory muscle dysfunction were still present at the last exercise test. Thirteen patients could complete the exercise test within seven days after discontinuation of PMV. Recovery rate was related to age, PMV days, severity of illness and presence of chronic medical conditions.
\end{abstract}

\section{KEY WORDS: PROLONGED MECHANICAL VENTILATION, EXERCISE TESTING.}

\section{INTRODUCTION}

Patients who receive prolonged mechanical ventilation (PMV) are most frequently nursed in intensive care units. Their medical care is therefore dependent on skilled personnel and sophisticated equipment. Mechanical ventilation is considered "prolonged" when five or more days of ventilator support is given (Higgins, 1998). The medical care can therefore often result in high financial costs (Fakhry et al, 1996). Jauhar (2001) reported that as medical technology improves and the age of populations rise, more patients are also receiving PMV. It is therefore possible that the use of PMV will escalate in the future. Due to the high-tech medical care involved, the financial implications and increased use of PMV, it seems justified to evaluate the outcome of these patients.

Little is known and documented regarding the physical recovery of patients who received PMV, especially with regard to the acute rehabilitation period following this intervention. Nava and Ambrosino (2000) encouraged physiotherapists working in intensive care units to measure parameters such as patients' physical limitations, severity of dyspnoea and pulmonary function tests in order to evaluate patient recovery. In
2003 Angus and Carlet also encouraged researchers to study the quality of life, functional status, morbidity and survival of intensive care patients after the period of critical illness. The outcome in critical care is measured by looking at patient mortality rates and quality of life (Fernandez et al, 1996). According to Heyland and Kutsogiannis (2000), the focus of outcome is also starting to move beyond survival and directed to how patients feel and function.

Severe weakness and functional impairment is extremely common in these intensive care patients (Angus and Carlet, 2003; Fletcher et al, 2003). This weakness is due to a combination of neuromuscular and cardio-respiratory factors. An acute stress incident, such as a critical illness, alters a patient's metabolic demand and increases catabolic processes in the body (Charney, 1995). McConachie (2000) noted that skeletal muscle atrophy occurs within a few days in the catabolic critically ill patient. Skeletal muscle atrophy is further promoted by physical inactivity caused by bed rest, sedation and/or paralysing agents during the critical illness. Numerous researchers (Bolton, 1996; Hund 1996 \& 1999; Witt et al, 1991) have identified the presence of ICU acquired neuromuscular abnormalities, such as critical illness polyneuropathy (CIP) and myopathy (CIM) in the critically ill ventilated patient. Functional recovery after a critical illness takes longer when CIP and/or CIM are present in a patient (Leijten et al, 1995; Lacomis et al, 1998). These patients' physical abilities are further influenced by the combined effects of the period of positive pressure ventilation and physical inactivity on the cardiovascular and respiratory systems.

A multidisciplinary approach is required during their recovery period (Scheinhorn et al, 2002). Physiotherapists play an integral part in the rehabilitation process due to the neuromuscular and cardio-respiratory challenges they face. Physical improvement in these patients can be assessed by an exercise test during the rehabilitation period. The

\section{CORRESPONDENCE TO:}

$\mathrm{H}$ van Aswegen

Physiotherapy Department

University of the Witwatersrand

7 York Road, Parktown 2193

Tel: (011) 717-3702

Fax: (011) 717-3719

E-mail: vanaswegenh@therapy.wits.ac.za 
assessment method can therefore be an exercise test fashioned specifically for this population group. Using the shuttlewalk test, step test or six-minute walking test is inappropriate at this stage due to the possible inability of the patients to walk initially.

The designed exercise test needs to start at a low activity level and then slowly progress to higher functional activities to accommodate for improvement in the neuromuscular status of these patients. Rashbaum et al (2001) supported functional exercise testing as an alternative option when individuals were only able to do low-level activities such as bed activities, transfers and wheelchair mobility.

Patients who have been on PMV often report symptoms such as breathlessness, weakness and effort when performing physical activities. Including an assessment tool such as the modified Borg scale (MBS) would enable patients to give a subjective rating of their perceived effort during the exercise test. This would enable clinicians to quantify patients' symptoms and understand the intensity of their subjective effort better. The MBS is noted to be a reliable and valid tool for assessing subjective perceived effort (Noble et al, 1983, Neely et al, 1992, AACVPR, 1999). This specific instrument was used in case studies in mechanically ventilated patients (Jacavone and Young, 1998; Lush et al, 1998) and in the period after prolonged ventilation (Roos et al, 2002) with good results.

Monitoring cardio-respiratory parameters in a patient who is critically ill is always indicated to ensure patient stability. Readmission to ICU is also often due to cardiocirculatory and respiratory problems (Metnitz et al, 2003). A "mobilization challenged test", such as turning or moving in bed, was encouraged by Dean in Pryor and Prasad (2002) to assess patients' cardio-respiratory response when recovering from a critical illness. In order to indicate the objective parameters of physical effort the assessment of cardio-respiratory parameters should therefore be included.

The physical recovery of patients who received PMV can then be measured by assessing the cardio-respiratory response to physical effort, subjective perceived effort evaluation and change in functional status.

The aims of this research study were therefore the following: (1) to establish if patients who had been critically ill and dependent on prolonged mechanical ventilation would be able to use the modified Borg scale to report their subjective perceived effort during functional exercise testing, (2) to establish if a correlation or trend existed between the patients' subjective perceived effort and physical effort (physiological parameters) and (3) to establish if an improvement in their physical ability reflected a relationship with their subjective perceived effort status over time. This study should provide additional information with regard to the recovery period of patients after PMV and during rehabilitation in the acute period.

\section{ETHICAL ISSUES}

The researcher applied for ethical clearance from the Committee for Research on Human subjects (medical) at the University of the Witwatersrand, Johannesburg. Ethical clearance was obtained unconditionally. Permission was also obtained from Sunninghill, Krugersdorp and Johannesburg hospitals to conduct the research at these specific hospitals.

\section{METHODOLOGY}

\section{Study design and sampling method}

This study was conducted over a sixmonth period from July 2002 to January 2003 at three venues in the Gauteng province; Johannesburg, Krugersdorp and Sunninghill hospitals.

A prospective correlation study using a consecutive sampling method was chosen. The selection of patients was dependent on specific inclusion and exclusion criteria.

The inclusion criteria consisted of the following:

(1) Patients were included if they were admitted to any of the intensive care units (ICU's) at Sunninghill hospital (trauma ICU, general surgical ICU and the coronary care unit) or Krugersdorp Hospital (medical ICU, surgical ICU and cardio thoracic ICU), but only included at Johannes- burg Hospital if they were admitted to the general ICU.

(2) Patients receiving invasive ventilator support for five days or longer via an endotracheal or tracheostomy tube.

(3) Patients aged between 18 to 80 years.

(4) Patients were only included if permission was obtained from their caring physician.

(5) Patients had to be able to give informed consent while being orientated to person and place with a Glasgow Coma Scale rating of 15/15. The exclusion criteria included any condition that prevented early mobilization after discontinuation of PMV. The following patients were excluded:

(1) Patients with spinal cord injuries.

(2) Patients with unstable pelvic or vertebral fractures

Conditions influencing patients' ability to give subjective feedback using the modified Borg scale were also considered grounds for exclusion. This included the following patients:

(1) Mentally handicapped patients

(2) Head injured patients.

(3) Pre-admission medical history of dementia, Alzheimer's disease or confusion.

(4) Illiterate subjects.

\section{Sample size}

In the six-month sampling period 111 patients were identified as possible study subjects. Five patients were excluded due to being illiterate and six patients due to being confused and disorientated to person and place three to seven days after discontinuation of PMV. Four patients were transferred to another hospital during PMV or shortly after this period. The caring physicians of eight patients could not be contacted for permission to include their patients. One patient died within a week of discontinuation of mechanical ventilation and fifty-three patients died during their PMV period. Three patients declined participation in the study. Thirty-one patients consented and were subsequently tested.

\section{Experimental procedure}

Weekly visits to the different ICU's were conducted to identify patients who 
received mechanical ventilation for five days or longer. Reviews of patients' medical diagnoses and medical status according to their medical charts were done. Nursing feedback with regard to patients' condition was also obtained. Once a specific patient was successfully extubated from PMV, the physician in charge of the patient was contacted and his/her permission for patient inclusion in the study obtained. Three to seven days after discontinuation of PMV the patients were interviewed and their informed consent gained. At this time it was also determined if the patients were adequately orientated to person and place and if they had a Glasgow Coma Scale score of $15 / 15$.

A general assessment focussing on the patient's medical chart, past medical history and the course of the patient's illness was documented. Patients performed the exercise test twice weekly until they were able to complete all the phases of the exercise test independently. The exercise-testing period did not exceed four weeks. If patients were discharged from the hospital before they could do the exercise test, testing continued at their homes.

The exercise test consisted of the following six functional activities:

Phase 1: Ankle dorsi-flexion to plantar flexion (10 repetitions).

Phase 2: Supine (trunk elevated 30 degrees) to side lying.

Phase 3: Side lying to sitting on the edge of the bed.

Phase 4: Sit to stand next to the bed.

Phase 5: Transfer bed to standing to sitting in a chair.

Phase 6: Walking 60 seconds.

Each exercise testing session started with phase one and progressed to phase six. The patients were instructed to complete each phase in the exercise test independently. An assistive device such as a bedrail, monkey chain or walking frame could be used to assist the patients during any phase of the test. If they were unable to complete or perform a phase in the exercise test the researcher stopped the session. Patients rated their subjective perceived effort to accomplish a phase in the exercise test using the modified Borg scale. The following cues were used to prompt the patients: "How hard did you work to complete the activity? How much effort did it take to complete the task?" The following physiological parameters were assessed to monitor the cardio-respiratory response to physical effort: heart rate, respiratory rate, blood pressure, peak expiratory flow rates and percutaneous oxygen saturation. These parameters were measured and documented at baseline and at specific phases in the exercise test.

\section{Equipment}

The following equipment was used during the exercise testing sessions: walking frame, bed rails, monkey chain, stopwatch, mini Wright peak flow meter with disposable mouth piece, Siemens percutaneous pulse oximeter, electrocardiogram equipment while in ICU, non-invasive blood pressure equipment while in ICU, stethoscope and sphygmomanometer.

\section{DATA ANALYSIS}

The research sample consisted of 31 patients but five patients $(16 \%)$ were lost to follow-up during the testing period. This was due to confounding variables: one patient was transferred to a rehabilitation hospital, one patient was transferred to another acute care hospital in the Orange Free State province, the third patient was discharged from the hospital to her home which was situated in the Orange Free State province and the last two patients became critically ill. One of these patients developed a vertebral abscess and the other a pancreatic abscess. Both patients required surgical intervention and further mechanical ventilation. The data of the remaining twenty-six patients $(84 \%)$ were included during statistical analysis.

\section{Statistical analysis}

The statistical analysis consisted of the following statistical tests: the Pearson's correlation coefficient (r), student's paired t-test and the Kaplan-Meier survival estimate. Descriptive statistics provided information on the research sample's characteristics. The strength of a linear relationship or association between the subjective parameter of effort and the objective parameters of effort was conducted using the last exercise testing session's data of the sample. This was necessary as each individual achieved the functional end point (phase six in the exercise test) at different intervals. The change in physiological parameters and subjective perceived effort ratings (MBS) from baseline to each specific phase of the exercise test was assessed with the student's paired t-test. This was carried out to determine if a trend in change existed between the objective parameters of effort (physiological parameters) and the subjective parameter of effort (MBS). The change in subjective effort rating of the sample over time was also determined using the student's paired t-test. The first exercise testing session's total mean MBS data of the sample was compared to the last exercise testing session's total mean MBS data. The level of significance used for the p-value of the above-mentioned tests was $<0.05$. The time in days it required an individual to be able to complete the exercise test after discontinuation of PMV was determined using a Kaplan-Meier survival estimate. This information provided the time factor to functional end point of the study.

\section{RESULTS}

\section{Sample characteristics}

The 26 patients consisted of 12 women (46\%) and 14 men (54\%). The mean age of the sample was $40.15 \mathrm{yrs} \pm 14.21$. The youngest patient was 19 years old and the oldest patient 66 years old. The mean time spent on mechanical ventilation (MV) was 19.54 days \pm 15.14 . The minimum number of days spent on MV was six days and the maximum was 75 days. The patients' pathologies were divided into the following categories: cardio-thoracic (five patients), abdominal surgery (seven patients), medical (five patients) and trauma (nine patients).

\section{Association between Objective/ Subjective parameters of effort}

\section{Subjective perceived effort}

The total mean MBS rating of phase one was 1.75 , which represented a verbal rating of "light" on the MBS. The total mean MBS rating of phase six was 4.8 representing a verbal rating of "heavy" on the MBS. 
Table 1: Pearson's correlation coefficient for phase one to six.

\begin{tabular}{|l|l|l|l|l|l|l|l|}
\hline & $\mathbf{n}$ & HR & SBP & DBP & RR & PEFR & SpO2 \\
\hline Phase 1 & 26 & 0.04 & -0.10 & -0.42 & 0.01 & 0.08 & -0.30 \\
\hline Phase 2 & 26 & 0.05 & & & 0.02 & -0.24 \\
\hline Phase 3 & 26 & 0.13 & 0.19 & 0.22 & 0.22 & -0.29 & -0.26 \\
\hline Phase 4 & 26 & -0.10 & & & 0.23 & 0.04 \\
\hline Phase 5 & 26 & -0.13 & -0.08 & -0.35 & 0.01 & 0.16 & -0.05 \\
\hline Phase 6 & 26 & -0.09 & -0.05 & -0.41 & -0.02 & 0.14 & -0.07 \\
\hline
\end{tabular}

* $\mathrm{n}$ (sample size), HR (heart rate), SBP (systolic blood pressure), DBP (diastolic blood pressure), RR (respiratory rate), PEFR (peak expiratory flow rate) and SpO 2 (percutaneous oxygen saturation).

Table 2: Modified Borg scale ratings during last exercise test.

\begin{tabular}{|l|l|l|l|l|}
\hline & $\mathbf{n}$ & $\begin{array}{l}\text { Total Mean MBS } \\
\text { ratings }\end{array}$ & $\begin{array}{l}\text { Standard } \\
\text { deviation }\end{array}$ & p - value \\
\hline Phase one & 26 & 1.75 & \pm 1.74 & - \\
\hline Phase two & 26 & 2.46 & \pm 2.04 & 0.02 \\
\hline Phase three & 26 & 2.75 & \pm 1.92 & 0.01 \\
\hline Phase four & 26 & 2.75 & \pm 1.95 & 0.01 \\
\hline Phase five & 26 & 3.29 & \pm 2.14 & 0.00 \\
\hline Phase six & 26 & 4.80 & \pm 2.12 & 0.00 \\
\hline
\end{tabular}

* n (sample size), MBS (modified Borg scale).

Table 3: Change in total MBS rating over time.

\begin{tabular}{|l|l|l|l|l|}
\hline & $\mathbf{n}$ & $\begin{array}{l}\text { Total mean MBS } \\
\text { ratings }\end{array}$ & $\begin{array}{l}\text { Standard } \\
\text { deviation }\end{array}$ & p-value \\
\hline First exercise test & 26 & 32.48 & \pm 17.74 & - \\
\hline Last exercise test & 26 & 18.00 & \pm 16.07 & 0.00 \\
\hline
\end{tabular}

* $\mathrm{n}$ (sample size), MBS (modified Borg scale).

Table 4: Baseline physiological parameters of the first and last exercise test.

\begin{tabular}{|l|l|l|}
\hline Physiological parameters & First ex ercise test & Last exercise test \\
\hline Sample size & 26 & 26 \\
\hline Mean HR \pm SD & $99.38 \mathrm{~b} / \mathrm{min} \pm 13.55$ & $98.96 \mathrm{~b} / \mathrm{min} \pm 13.79$ \\
\hline Mean SBP \pm SD & $126.20 \mathrm{mmHg} \pm 18.32$ & $125.77 \mathrm{mmHg} \pm 16.91$ \\
\hline Mean DBP \pm SD & $76.54 \mathrm{mmHg} \pm 11.40$ & $75.88 \mathrm{mmHg} \pm 11.46$ \\
\hline Mean RR \pm SD & $26.19 \mathrm{~b} / \mathrm{min} \pm 6.44$ & $26.08 \mathrm{~b} / \mathrm{min} \pm 5.99$ \\
\hline Mean PEFR \pm SD & $150.00 \mathrm{l} / \mathrm{min} \pm 99.32$ & $201.60 \mathrm{l} / \mathrm{min} \pm 105.66$ \\
\hline Mean SpO $2 \pm S D$ & $93.23 \% \pm 5.10$ & $93.39 \% \pm 4.83$ \\
\hline
\end{tabular}

\section{Objective parameters of effort}

By comparing the baseline mean physiological values from the first and the last exercise test the change in the cardiorespiratory status of the research sample over time was highlighted.
The change in heart rate from baseline was significant $(p<0.05)$ at each phase in the exercise test. A significant change in respiratory rate was noted at phase two, five and six. The change in systolic blood pressure was significant at phase three, five and six. A signifi- cant change in percutaneous oxygen saturation was noted after phase one. No significant change in diastolic blood pressure and peak expiratory flow rates were noted during the six phases of the functional exercise test. 
Table 5: Physiological response during the six-phase functional exercise test.

\begin{tabular}{|c|c|c|c|c|c|c|}
\hline Phase 1 & $\mathbf{n}$ & Baseline Mean & \pm SD & Mean & \pm SD & p-value \\
\hline $\mathrm{HR}$ & 26 & $98.96 \mathrm{~b} / \mathrm{min}$ & \pm 13.79 & $102.92 \mathrm{~b} / \mathrm{min}$ & \pm 14.67 & 0.01 \\
\hline SBP & 26 & $125.77 \mathrm{mmHg}$ & \pm 16.91 & $123.39 \mathrm{mmHg}$ & \pm 17.63 & 0.09 \\
\hline DBP & 26 & $75.89 \mathrm{mmHg}$ & \pm 11.46 & $75.42 \mathrm{mmHg}$ & \pm 12.66 & 0.66 \\
\hline $\mathrm{RR}$ & 26 & $26.08 \mathrm{~b} / \mathrm{min}$ & \pm 5.99 & $26.39 \mathrm{~b} / \mathrm{min}$ & \pm 5.89 & 0.62 \\
\hline PEFR & 26 & $201.601 / \mathrm{min}$ & \pm 105.66 & $197.501 / \mathrm{min}$ & \pm 85.38 & 0.32 \\
\hline $\mathrm{SpO} 2$ & 26 & $93.39 \%$ & \pm 4.83 & $94.04 \%$ & \pm 4.26 & 0.02 \\
\hline \multicolumn{7}{|l|}{ Phase 2} \\
\hline$H R$ & 26 & $98.96 \mathrm{~b} / \mathrm{min}$ & \pm 13.79 & $103.85 \mathrm{~b} / \mathrm{min}$ & \pm 14.43 & 0.00 \\
\hline $\mathrm{RR}$ & 26 & $26.08 \mathrm{~b} / \mathrm{min}$ & \pm 5.99 & $28.31 \mathrm{~b} / \mathrm{min}$ & \pm 5.24 & 0.00 \\
\hline SpO 2 & 26 & $93.39 \%$ & \pm 4.83 & $93.62 \%$ & \pm 4.76 & 0.34 \\
\hline \multicolumn{7}{|l|}{ Phase 3} \\
\hline$H R$ & 26 & $98.96 \mathrm{~b} / \mathrm{min}$ & \pm 13.79 & $110.92 \mathrm{~b} / \mathrm{min}$ & \pm 12.83 & 0.00 \\
\hline SBP & 26 & $125.77 \mathrm{mmHg}$ & \pm 16.91 & $120.42 \mathrm{mmHg}$ & \pm 17.94 & 0.02 \\
\hline DBP & 26 & $75.89 \mathrm{mmhg}$ & \pm 11.46 & $75.81 \mathrm{mmHg}$ & \pm 13.88 & 0.97 \\
\hline $\mathrm{RR}$ & 26 & $26.08 \mathrm{~b} / \mathrm{min}$ & \pm 5.99 & $27.92 \mathrm{~b} / \mathrm{min}$ & \pm 7.38 & 0.09 \\
\hline PEFR & 26 & $201.601 / \mathrm{min}$ & \pm 105.66 & $210.801 / \mathrm{min}$ & \pm 94.47 & 0.44 \\
\hline $\mathrm{SpO} 2$ & 26 & $93.39 \%$ & \pm 4.83 & $93.19 \%$ & \pm 4.86 & 0.61 \\
\hline \multicolumn{7}{|l|}{ Phase 4} \\
\hline$H R$ & 26 & $98.96 \mathrm{~b} / \mathrm{min}$ & \pm 13.79 & $110.62 \mathrm{~b} / \mathrm{min}$ & \pm 14.67 & 0.00 \\
\hline $\mathrm{RR}$ & 26 & $26.08 \mathrm{~b} / \mathrm{min}$ & \pm 5.99 & $27.73 \mathrm{~b} / \mathrm{min}$ & \pm 6.16 & 0.08 \\
\hline SpO 2 & 26 & $93.39 \%$ & \pm 4.83 & $93.58 \%$ & \pm 4.13 & 0.72 \\
\hline \multicolumn{7}{|l|}{ Phase 5} \\
\hline$H R$ & 26 & $98.96 \mathrm{~b} / \mathrm{min}$ & \pm 13.79 & $112.15 \mathrm{~b} / \mathrm{min}$ & \pm 14.83 & 0.00 \\
\hline SBP & 26 & $125.77 \mathrm{mmHg}$ & \pm 16.91 & $118.73 \mathrm{mmHg}$ & \pm 18.26 & 0.00 \\
\hline DBP & 26 & $75.89 \mathrm{mmHg}$ & \pm 11.46 & $72.81 \mathrm{mmHg}$ & \pm 13.61 & 0.25 \\
\hline $\mathrm{RR}$ & 26 & $26.08 \mathrm{~b} / \mathrm{min}$ & \pm 5.99 & $28.23 \mathrm{~b} / \mathrm{min}$ & \pm 5.57 & 0.03 \\
\hline PEFR & 26 & $201.601 / \mathrm{min}$ & \pm 105.66 & $203.201 / \mathrm{min}$ & \pm 100.11 & 0.89 \\
\hline $\mathrm{SpO} 2$ & 26 & $93.39 \%$ & \pm 4.83 & $93.31 \%$ & \pm 4.89 & 0.84 \\
\hline \multicolumn{7}{|l|}{ Phase 6} \\
\hline $\mathrm{HR}$ & 25 & $98.96 \mathrm{~b} / \mathrm{min}$ & \pm 13.79 & $118.20 \mathrm{~b} / \mathrm{min}$ & \pm 15.60 & 0.00 \\
\hline SBP & 25 & $125.77 \mathrm{mmHg}$ & \pm 16.91 & $120.80 \mathrm{mmHg}$ & \pm 18.25 & 0.01 \\
\hline DBP & 25 & $75.89 \mathrm{mmHg}$ & \pm 11.46 & $75.32 \mathrm{mmHg}$ & \pm 11.76 & 0.67 \\
\hline $\mathrm{RR}$ & 25 & $26.08 \mathrm{~b} / \mathrm{min}$ & \pm 5.99 & $32.32 \mathrm{~b} / \mathrm{min}$ & \pm 6.19 & 0.00 \\
\hline PEFR & 25 & $201.601 / \mathrm{min}$ & \pm 105.66 & $200.801 / \mathrm{min}$ & \pm 109.27 & 0.96 \\
\hline $\mathrm{SpO} 2$ & 25 & $93.39 \%$ & \pm 4.83 & $93.48 \%$ & \pm 4.28 & 0.74 \\
\hline
\end{tabular}

* $\mathrm{n}$ (sample size), HR \pm heart rate), SBP (systolic blood pressure), DBP \pm diastolic blood pressure), RR (respiratory rate), PEFR $\pm p$ eak expiratory flow rate) and SpO 2 (percutaneous oxygen saturation). 
Table 6: Kaplan-Meier survival estimate data.

\begin{tabular}{|l|l|l|l|}
\hline Time off PMV & Total $\mathbf{n}$ at beginning & $\begin{array}{l}\text { Number of patients } \\
\text { who completed test }\end{array}$ & Survival function \\
\hline 3 days & 26 patients & 2 & $92 \%$ \\
\hline 4 days & 24 patients & 8 & $62 \%$ \\
\hline 5 days & 16 patients & 1 & $58 \%$ \\
\hline 6 days & 15 patients & 1 & $54 \%$ \\
\hline 7 days & 14 patients & 1 & $50 \%$ \\
\hline 8 days & 13 patients & 2 & $42 \%$ \\
\hline 9 days & 11 patients & 3 & $31 \%$ \\
\hline 11 days & 8 patients & 1 & $27 \%$ \\
\hline 15 days & 7 patients & 3 & $15 \%$ \\
\hline 16 days & 4 patients & 1 & $12 \%$ \\
\hline 19 days & 3 patients & 1 & $8 \%$ \\
\hline 25 days & 2 patients & 1 & $4 \%$ \\
\hline 28 days & 1 patient & 0 & $4 \%$ \\
\hline
\end{tabular}

* PMV (prolonged mechanical ventilation), n (sample size).

\section{Functional recovery rate}

One patient was unable to reach the functional end point within the 28 days time frame set aside for exercise testing. Thirteen patients $(50 \%)$ were able to complete the exercise test within seven days after discontinuation of PMV.

\section{DISCUSSION}

The purpose of the study was to assess the physical recovery of patients who received PMV by assessing their cardiorespiratory and subjective perceived effort response to physical effort with a six-phase functional exercise test after the period of PMV.

\section{Subjective and Objective effort}

The patients used the MBS as communication tool to report their subjective perceived effort during the phases of the exercise test. The changes in subjective perceived effort from phase to phase were significant with a p-value $<0.05$ at each phase and changing to a more significant p-value level as they progressed. Objective signs of increased physical effort were also noted during phase progression. Changes in heart rate was statistically significant at every phase and changes in respiratory rate at phase two, five and six but the level of significance of the parameters also increased with progression through the functional exercise test. These changes indicate increased physical effort. A significant decrease in systolic blood pressure was also noted at phases three, five and six. These phases were in the sitting and standing position and could be due to orthostatic intolerance. Patients also reported dizziness in variable degrees when they moved from a supine to a standing position. A decrease in peak expiratory flow rates was noted from phases three to five to six. Even though it was not statistically significant the decline in this parameter also demonstrated increased respiratory effort. Patients in the research group were of the opinion that they were experiencing more subjective effort when at the same time increased physical signs of effort were also demonstrated as they progressed through the exercise test. The six-phase functional exercise test can thus be regarded as an exercise test of progressing difficulty in the PMV population.

A statistically significant $(\mathrm{p}<0.00)$ decrease in subjective perceived effort ratings from the first to the last exercise test was noted. This suggests that the exercise test was perceived to require less effort as the patients' functional ability improved. It is unclear in what way change in self-confidence affected the patients' physical ability and ratings of perceived effort. Self-efficacy (a patient's confidence in being able to perform a specific activity) was noted to be a better indicator of physical activity than physical fitness (measured as peak VO2) and perceived effort during activity in chronic heart failure patients (Oka et al, 1996). A critical illness combined with a prolonged period of physical inactivity will influence an individual's self-confidence. It is therefore possible that self-efficacy influenced the PMV patients' physical ability and perceived effort ratings. Further study in this area is needed.

Minimal improvements were noted in cardio-respiratory parameters over time as indicated by the baseline measurements from the first and last exercise test. This finding supports information provided by Hough (1997) that reconditioning in the cardiovascular and respiratory systems takes longer than in the musculoskeletal system of patients who were exposed to prolonged physical inactivity. The largest improvement was noted in the peak expiratory flow rate (PEFR). The PEFR measurement was 
included in the exercise test as a means to evaluate the ability of the patients' respiratory muscles to ventilate their lungs. The improvement could be due to the patients perfecting their technique or more likely to the improvement in their neuromuscular status over time as is also supported by their ability to complete the exercise test. Even though this value increased over time it was still below the normal range for adults of 300-600 1/min (Hough, 1997). Prolonged mechanical ventilation leads to respiratory muscle dysfunction (Bruton et al, 2002) and this situation are further influenced by physical inactivity. Bed rest alters respiratory muscle strength as was demonstrated by Puckree et al (2000). The below normal PEFR could thus be due to respiratory muscle weakness. This scenario was further supported by patients' increased resting respiratory rates. When respiratory muscle dysfunction is present the preferred option to increase ventilation is increasing respiratory rate and not tidal volume (Hasson, 1994). This research finding indicates that the sample was still at risk of developing acute neuromuscular respiratory failure (NM-ARF). Latronico et al (1999) identified this condition in prolonged intensive care stay survivors four to seven days after discharge from ICU. Clinical signs of NM-ARF include breathlessness, tachypnoea, and muscle weakness with normal arterial blood gases until a critical level of NM-ARF is reached. The $\mathrm{PaO}_{2}$ level of the research sample was $70 \mathrm{mmHg}$ indicating mild hypoxemia (Wilkins et al, 1995; Pryor and Prasad, 2002). The $\mathrm{PaO}_{2}$ level of the research group was determined using the oxygen dissociation curve, mean temperature (36.66 degrees Celsius) and baseline SpO2 level of $93.39 \%$. Respiratory muscle training is therefore still indicated even if patients are able to complete the six-phase functional exercise test. Further study is needed to assess how long cardio-respiratory recovery takes until a normal status is reached.

No linear correlation between the subjective parameter of effort (MBS) and objective signs of effort (physiological parameters) was noted from phase one to six of the exercise test. The only level of significance $(p<0.05)$ was noted between diastolic blood pressure and MBS at phase one $(r=-0.42, p<0.03)$ and at phase six $(r=-0.41, p<0.04)$. This suggested that perceived effort ratings increase when diastolic blood pressure measurements decreased at these phases.

The lack of correlation between subjective perceived effort and physiological parameters is supported by research done in chronic renal failure patients (Fitts \& Guthrie, 1995) and chronic heart failure patients (Oka et al, 1993). This finding in the PMV, CHF and $\mathrm{CRF}$ populations could be due to similar abnormalities in the cardiorespiratory and neuromuscular systems. Skeletal muscle atrophy is prevalent in the $\mathrm{CHF}$ and $\mathrm{CRF}$ population due to body deconditioning caused by pacing physical activity according to subjective symptoms such as breathlessness and fatigue (Hasson, 1994; Humphrey et al, 2001; Oka et al, 1993). Decreased lung compliance is often present in both groups due to pulmonary oedema. Cardiac function is also altered such as left ventricular dysfunction in $\mathrm{CHF}$ resulting in a drop in cardiac output (Humphrey et al, 2001). The research sample's cardio-respiratory response to activity was influenced by the inactivity period and prolonged use of positive pressure ventilation. Possible CVS changes therefore were a drop in cardiac output, stroke volume and decreased left ventricular function (Bortz, 1982; McConachie, 2000). The elevated baseline heart rate supports the possible drop in cardiac output and stroke volume in the sample. The presence of neuromuscular abnormalities in the PMV population can also not be excluded as demonstrated by PEFR and RR measurements during the exercise test and time required to physically complete the test. Even though no correlation existed between the subjective and objective parameters of effort it was of value to include both aspects of effort to evaluate physical stress in the PMV population.

It is important to measure physical stress objectively but also to be aware of changes in the subjective symptoms of patients during a challenging physical activity. This is especially true in the acute care environment where patients could be recovering from a critical illness. Rating the patients perceived effort with the modified Borg scale provided insight into their subjective feeling of physical effort and the intensity of this symptom.

\section{Functional Status}

The functional end point in this study was phase six of the exercise test. Thirteen patients $(50 \%)$ could perform the six-phase functional exercise test within seven days after discontinuation of PMV. In the remaining patients, twelve patients could complete the test within twenty-five days. The last patient was unable to accomplish the exercise test in the four weeks set aside for testing. Twenty patients (77\%) achieved the functional end point prior to discharge home and six patients $(23 \%)$ did not. Five patients went home and the last was transferred to a rehabilitation hospital. The preadmission medical histories and course of the patients' critically ill periods were reviewed to determine possible explanations as to why the functional recovery rates were different. Group one could do the test within one week and group two could not.

Group one was younger (30.85 yrs \pm 7.40), spent less time on mechanical ventilation $(11.77 \pm 5.04)$ and did not have chronic obstructive pulmonary disease or chronic cardiac failure as preadmission medical conditions. No incident of acute renal failure or medical diagnosis of sepsis was recorded in group one during their critically ill period. The pathologies in this group included the following: trauma (six patients), cardio-thoracic (four patients), medical (one patient) and abdominal surgery (2 patients).

Group two was older (49.46 yrs \pm 13.34), was ventilated longer (27.31 days \pm 17.92 ) and had preadmission medical conditions such as COPD (three patients) and CCF with COPD (one patient). In group two, four patients developed acute renal failure during their critically ill period, which required dialysis. Four patients in this group also had medical diagnoses related to sepsis. One of these patients was also one of the patients that developed renal failure. The pathologies in this group were as 
follow: trauma (three patients), cardiothoracic (one patient), medical (four patients) and abdominal surgery (five patients).

Numerous researchers (Spicher \& White, 1987; Engoren et al, 2000; Miller et al, 2000) indicated that age is a predictor of mortality and morbidity after PMV. Group two was older and this could account for a slower physical recovery. Due to group two being ventilated longer one can assume that their period of physical inactivity was longer and this therefore led to increased cardio-respiratory deconditioning and skeletal muscle atrophy. A fear of falling during phases three to six could therefore have influenced this group's selfefficacy more. Severity of illness in this group was worse due to the incidences of acute renal failure and sepsis. Acute renal failure is rarely seen as a single organ insufficiency in the critically ill and more often associated with multiorgan dysfunction syndrome and sepsis (McConachie, 2000). Engoren et al (2000) also found that patients in their study that had post-operative renal failure after cardiac surgery were more debilitated and unable to walk initially. Critical illness polyneuropathy (CIP) was identified in ventilated patients who had multi-organ dysfunction syndrome, sepsis or systemic inflammatory response syndrome (Witt el al, 1991; Bolton, 1996). CIP is associated with renal failure $(\mathrm{p}=0.04)$ and number of ventilation days $(\mathrm{p}=0.02)$ (Leijten et al 1996). It is therefore possible that this ICU acquired neuromuscular abnormality was present in group two. This could have resulted in slower functional recovery. This diagnosis is only suggested and electromyography studies must be carried out to diagnose CIP conclusively. EMG studies were outside the scope of this research study.

\section{CONCLUSIONS}

The findings of this study showed that patients who received PMV could use the modified Borg scale to communicate their subjective perceived effort during the six-phase functional exercise test. It was especially beneficial to highlight the intensity of their subjective symptom. Statistical analysis indicated no linear correlation between the subjective parameters of effort and objective parameters of effort during the six phases of the exercise test. The six-phase functional exercise test seems to be a test of progressing difficulty as indicated by change in subjective perceived effort ratings and objective signs of effort (heart rate and respiratory rate responses). The group's subjective perceived effort ratings decreased over time as their physical ability improved. Minimal improvement was noted in cardio-respiratory status over time. It can therefore be concluded that neuromuscular cues influenced the process of perceived effort rating in the PMV population more than cardio-respiratory cues. The influence of self-efficacy cannot be excluded but further study in this area is needed. Signs of respiratory muscle weakness were still present at their last exercise test. The ability of patients to achieve the functional end point in this study was related to age, length of PMV, severity of illness and chronic medical conditions.

It therefore seems beneficial to include the six-phase functional exercise test in the rehabilitation process of these patients whose physical recovery is anticipated to take longer.

\section{ACKNOWLEDGEMENTS}

The researcher would like to thank the following individuals who assisted during the course of the research project:

The management offices of Sunninghill, Krugersdorp and Johannesburg Hospitals for their permission to conduct the research at these hospital sites.

The physiotherapy practices of Jenny Bowles, Dawn Hansen and Ronel Venter for their interest and support.

Family and friends for their support and interest in the research project.

Patients who participated in this research project, for allowing the researcher to study and track their physical recovery, without them this project would never have taken place.

\section{REFERENCES}

American Association of Cardiovascular \& Pulmonary Rehabilitation 1999 Exercise test protocols: pp. 60-64. In: Guidelines for Cardiac Rehabilitation and secondary prevention programs. 3rd ed. Human Kinetics Publishers, Inc

Angus DC, Carlet J 2003 Surviving intensive care: a report from the 2002 Brussels roundtable. Intensive Care Medicine 29:368-377

Bolton CF 1996 Sepsis and the systemic inflammatory response syndrome: neuromuscular manifestations. Critical Care Medicine 24: $1408-1416$

Bortz WM 1982 Disuse and aging. Journal of the American Medical Association 248 (10): 1203-1206

Charney P 1995 Nutrition assessment in the 1990's: where are we now? Nutrition in Clinical Practice 10: 131-139

Engoren M, Buderer NF, Zacharias A 2000 Long-term survival and health status after prolonged mechanical ventilation after cardiac surgery. Critical Care Medicine 28:2742-2748

Fakhry M, Kercher KW, Rutledge R 1996 Survival, Quality of life and charges in critically ill surgical patients requiring prolonged ICU stays. Journal of Trauma: Injury, Infection and Critical care 41 (6): 999-1007

Fernandez RR, Sanchez Cruz JJ, Vazquez Mata G 1996 Validation of a quality of life questionnaire for critically ill patients. Intensive Care Medicine 11: 1034-1042

Fitts SS, Guthrie MR 1995 Six-minute walk by people with chronic renal failure American Journal of Physical Medicine and Rehabilitation 74 (1): 54-58

Fletcher SN, Kennedy DD, Ghosh IR, Kiff K, Coakley JH, Hinds CJ 2003 Persistent neuromuscular and neurophysiologic abnormalities in long-term survivors of prolonged critical illness. Critical Care Medicine 31 (4): 1012-1016

Hasson SM 1994 Congestive cardiac failure: pp. 141-142; Renal failure: pp. 142-143, 187 188. In: Clinical Exercise Physiology. MosbyYear Book, Inc

Heyland DK, Kutsogiannis DJ 2000 Quality of life following critical care: moving beyond survival. Intensive Care Medicine 26:11721175

Higgins PA 1998 Patient perception of fatigue while undergoing long-term mechanical ventilation: incidence and associated factors. Heart \& Lung 27 (3): 177-182 
Hough A 1997 Effects of bed rest: pp. 18-19; Respiratory function tests: pp. 43-47. In: Physiotherapy in respiratory care. 2nd ed. Cheltenham: Stanley Thornes (Publishers) Ltd

Humphrey R, Bartels MN 2001 Exercise, Cardiovascular Disease and Chronic Heart Failure. Archives of Physical Medicine and Rehabilitation 82: S76-79

Hund EF 1996 Neuromuscular complications in the ICU: the spectrum of critical illnessrelated conditions causing muscular weakness and weaning failure. Journal of the Neurological Sciences 136:10-16

Hund E 1999 Myopathy in critically ill patients. Critical Care Medicine 27: 2544-2547

Jacavone J, Young J 1998 Use of pulmonary rehabilitation strategies to wean a difficultto-wean patient: case study. Critical Care Nurse 18 (6): 29-36

Jauhar S 2001 As technology improves, more people breathe with machines. The New York Times, April 24, p.7

Lacomis D, Petrella JT, Giuliani MJ 1998 Causes of neuromuscular weakness in the intensive care unit: a study of ninety-two patients. Muscle \& Nerve 21:610-617

Latronico N, Guarneri B, Alongi S, Bussi G, Candiani A 1999 Acute neuromuscular respiratory failure after ICU discharge. Intensive Care Medicine 25: 1302-1306

Leijten FSS, Harick-de Weerd JE, Poortvliet DC, De Weerd AW 1995 The role of poly neuropathy in motor convalescence after prolonged mechanical ventilation. Journal of the American Medical Association 274 (15): 1221-1225

Leijten FSS, De Weerd AW, Poortvliet DCJ, De Ridder VA, Ulrich C, Harick-De Weerd JE 1996 Critical illness polyneuropathy in multiple organ dysfunction syndrome and weaning from the ventilator. Intensive Care Medicine 22: $856-861$

Lush MT, Janson-Bjerklie S, Carrieri VK, Lovejoy N 1988 Dyspnea in the ventilatorassisted patient. Heart \& Lung 17: 528-535

McConachie I 2000 Mechanical ventilation: pp. 49-55; Acute renal failure: p. 162. In: Handbook of ICU therapy. London: Greenwich Medical Media Ltd

Metnitz PGH, Fieux F, Jordan B, Lang T, Moreno R, Gall JR 2003 Critically ill patients readmitted to intensive care units-lessons to learn? Intensive Care Medicine 29: 241-248

Miller RS, Patton M, Graham RM, Hollins H 2000 Outcome of trauma patients who survive prolonged lengths of stay in the intensive care unit. Journal of Trauma: Injury, Infection and Critical Care 48 (2): 229-234

Nava S, Ambrosino N 2000 Rehabilitation in the ICU: the European phoenix. Intensive Care Medicine 26: 841-844

Neely G, Ljunggren G, Sylven C, Borg G 1992 Comparison between the visual analogue scale (VAS) and the category ratio scale (CR-10) for the evaluation of leg exertion. International Journal of Sports Medicine 13: 133-136

Noble BJ, Borg G, Jacobs I, Ceci R, Kaiser P 1983 A category-ratio perceived exertion scale: relationship to blood and muscle lactates and heart rate. Medicine and Science in Sports and Exercise 15 (6): 523-528

Oka RK, Stotts NA, Dae MW, Haskell WL, Gortner SR 1993 Daily physical activity levels in congestive heart failure. American Journal of Cardiology 71: 921-925

Oka RK, Gortner SR, Stotts NA, Haskell WL 1996 Predictors of physical activity in patients with chronic heart failure secondary to either ischemic or idiopathic dilated cardiomyopathy. American Journal of Cardiology 77: $159-163$

Pryor J, Prasad SA 2002 Objective assessment: pp. 10-11; Mobilization: pp. 151-152. In: Physiotherapy for respiratory and cardiac problems. 3rd ed. London: Harcourt Publishers Limited

Puckree T, Moonasur R, Govender K 2000 Bedrest alters respiratory muscle strength in patients immobilized due to fractured femurs. South African Journal of Physiotherapy 56: $27-30$

Rashbaum IG, Walker WC, Glassman SJ 2001 Cardiopulmonary rehabilitation and cancer rehabilitation; cardiac rehabilitation in disabled populations. Archives of Physical Medicine and Rehabilitation 82 (1): S52-S55

Roos R, van Aswegen H, Eales CJ 2002 Perceived effort of functional activities after a period of mechanical ventilation. South African Journal of Physiotherapy 58 (4): pp. 33-36

Scheinhorn DC, Chao DC, Stearn-Hassenpflug M 2002 Liberation from prolonged mechanical ventilation. Critical Care Clinics 18: 569-595

Spicher JE, White DP 1987 Outcome of function following prolonged mechanical ventilation. Archives of Internal Medicine 147:421-425

Witt NJ, Zochodne DW, Bolton CF, Grand'Maison F, Wells G, Young B, Sibbald WJ 1991 Peripheral nerve function in sepsis and multiple organ failure. Chest 99: 176-184

Wilkins RL, Krider SJ, Sheldon RL 1995 Arterial blood sampling: pp. 105-109. In: Clinical assessment in Respiratory Care. 3rd ed. St. Louis: Mosby-Year Book, Inc

\section{Be there! CPRG's first Annual General Meetings}

\section{Lecture on physiotherapy in the critical care setting by Heleen van Asw egen (application for CPD accreditation lodged)}

The first Annual General Meeting of the CPRG-SGP (Cardio-Pulmonary Rehabilitation Group - South Gauteng Province) will be held on the Thursday evening, 29 April 2004. It will be preceded by a discussion held by an experienced lecturer, Heleen van Aswegen, on her area of expertise, physiotherapy in the critical care setting.

Members and other interested persons all welcome. Tea will be served.

Time: $\quad 18: 00$

Venue: $\quad$ Lecture Theatre, Conacher Block, Wits Education campus, St. Andrews Road, Parktown. (formerly the JCE campus)

Please RSVP: Linda /Claudeen: 011 884-5548

The National AGM for the Cardiopulmonary Rehabilitation Group of South Africa will be held on Satuday 8 May 2004 at 09:00am. Representatives and members from the other provinces with CPRG interest groups are invited. South Gauteng is hosting it this year and this is an opportunity for all members to get involved and meet fellow physiotherapists with the same interests and concerns as you! Venue: Conacher Block, Wits Education Campus, St. Andrews Road, Parktown.

Tea will be served. Accommodation enquiries: Natasha Nel, 0824486673

Please RSVP: Linda /Claudeen, 011 884-5548 


\section{THINKING OF WORKING OVERSEAS?}

\section{Let us help}

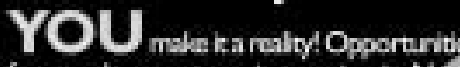
for employment are increasing in $\mathrm{N}$. Zealand, Australia, Europe, USA : Canada.

largest healthcare staffing
compary.
Whether it is to enhance your
career, travel the world, earn
great monoy or a mix of all these
things - the MATCH Group
aims to offer something for
everyonel

We look forward to hearing from interested

Social workers, Physlotheraplsts, Nurses, Doctors, Occupational Therapists, Aadiographers, Speech Therapists, Alediologists, Pharmacists and Teachers.

Cape Town: 0214222895

Email: match,capetown@worldonline,co.ra \#MATCH GROUP Q Qunur

\section{Sas \\ RELOCATION PROGRAMME}

We will assisi you wifth permits, lights, acxumumodation and Iravel to le'p make the move stress-tree.

Contact Sherrie Flury shernefigiprs.co.z. (t) 702714 BBS 2032 (f) 0027113261755 for moce information.

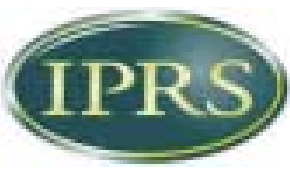

WWw.JPRS, ux,cem
LEADING THE FIELD IN PHYSIOTHERAPY

IPRS are the leading light in Injuny Prevention and Rehabilitation services in the UK and South Africa, and we are presently recruiting Physiatherapists to work in a number of locations throughout the United Kingdom.

The very feal shortage of skilled rehabilitation specialists in the UK means thare are a wealth of opportunities for the right individuals. Benefits to you include:

- Relocation assistance

- Excelleri mantiv pay

- Immediale start

- Nationuide postlons

- 4 days free training per year

- Temporary and permanent postions
MITA MEDTCAT Spocialnts in Clobar Heatheara Ancruimant Your ticket to a giobal future

Excellent opportunities in the UK and Middle East for:

\section{Occupational Therapists}

\section{Physiotherapists}

MTA Medical offers you:

6 Excelent rates of pay

(Middle Eastem salaries are tax-free?

4. Ful refund on your HPC UK registration fee aher only 12 weeks of werking through MTA in the UK

- Assistance with professional registration

4 Assigtance with visa/work permit agplications

4. Assistance in sourcing suitable accommodation (free accommodation in the Middle East)

4 Assistance with travel bookings

4. Assistance with opening bank accounts

4 Detailed infarmation on living and working abroad

\section{Patient not feeling as well as a Thomson's Gazelle? Try REITZER'S MUSCLE - $\ln \mathrm{Gel}$
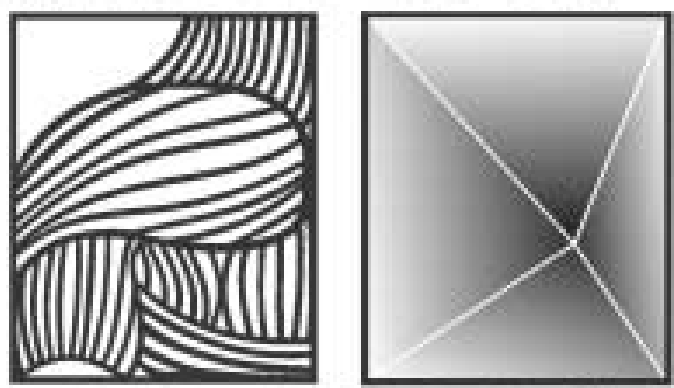 \\ High Concentration Arnica Oil Non-Sticky Ideal for Massaging}

For use with all electronic treatment equipment Reduce the Swell with Muscle-In Gel $R_{R=R}^{P}$ For more information or a sample, fax or e-mail us with your name, postal \& physical address. Fax: (011) 444-9386

E-mail: infogreitzer.co.za 